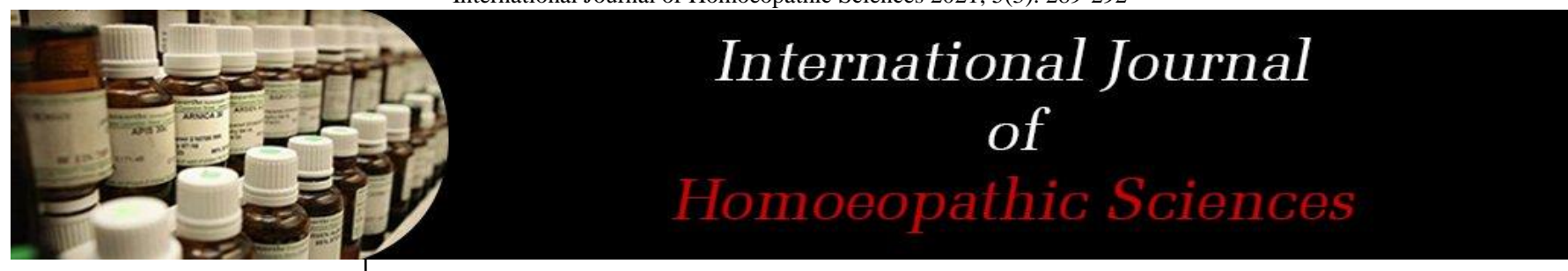

E-ISSN: $2616-4493$ P-ISSN: 2616-4485 www.homoeopathicjournal.com IJHS 2021; 5(3): 289-292 Received: 04-05-2021

Accepted: 06-06-2021

Dr. Sonia Parmar

P.G Part 2 student, Department of Pediatrics Guru Mishri Homoeopathic Medical College and Hospital and Research Centre, Shelgaon, Maharashtra University of Health Sciences Nashik, Maharashtra, India

Dr. Nowani Shaikh

Professor, P.G Guide, Head of Department. Department of Pediatrics. Guru Mishri Homoeopathic Medical College and Hospital and Rcentre, Shelgaon Maharashtra University of Health Sciences, Nashik, Maharashtra, India
Corresponding Author:

Dr. Sonia Parmar

P.G Part 2 student, Department of Pediatrics Guru Mishri Homoeopathic Medical College and Hospital and Research Centre, Shelgaon, Maharashtra University of Health Sciences Nashik, Maharashtra, India

\section{Risks and consequences of childhood and adolescent obesity}

\section{Dr. Sonia Parmar and Dr. Nowani Shaikh}

DOI: https://doi.org/10.33545/26164485.2021.v5.i3e.436

\begin{abstract}
Researchers are gradually becoming aware of the gravity of the risk that overweight and obesity pose for children's health. The incidence of chronic disease is escalating much more rapidly in developing countries and a potential threat in emerging incidence of childhood obesity. Globally, in 2010 there were estimated to be over 42 mill overweight children below the age of 5, and 35 mill of them are from developing countries. It was estimated $10 \%$ of school children, between age of 5 and 17 yrs of age are overweight and obese. Approximately $70 \%$ of obese adolescents group to become obese adults. Various studies done in India indicates a rising trend in the prevalence of overweight and obesity in children and adolescents. India have major implications towards widespread of non-communicable disease like diabetes, hypertension and cardiovascular disease in early adulthood. The association of obesity with type 2 diabetes in adolescents and children is very strong and confirmed by various studies. Evidence shows that obesity driven type 2 diabetes might become the most common form of newly diagnosed diabetes in adolescent youth within 10 yrs. Type 2 diabetes mellitus had been a disease of adults but now is occurring in increased numbers among obese adolescents. Studies also shows that there is an increased risk of nephropathy and early signs of cardiovascular disease in youth with type 2 diabetes. Definition: Itis defined as an excess of body fat. OR Obesity is also defined as a $20 \%$ excess of calculated ideal weight for age, sex and height of a child.
\end{abstract}

Keywords: Obesity, child metabolic syndrome x, genetic factors, maternal smoking, pregnancy.

\section{Introduction}

Obesity has emerged as one of the global health problems. Latest research conducted has shown that children start showing signs of atherosclerosis as early as 11 yrs of age and this is a extremely worrisome.

Obesity is one of the major risk factor for cardiovascular diseases, pulmonary diseases, metabolic diseases such as diabetes and dyslipidaemia, osteoarticular disease, and cancer. It is also seen that childhood obesity is associated with early onset type 2 diabetes.

There are several evidences showing the following associated with childhood and adolescence obesity;

1) Genetic component

2) Diabetes in pregnancy

3) Maternal smoking

4) High birth weight

5) Rapid infant weight gain, associated with low birth weight

6) Consumption of sugar-sweetened beverages

7) Physical inactivity and sedentary behaviour

8) Inadequate sleep

Some medications like cortisol, illnesses like hypothyroidism and syndromes like Prader Willi syndrome, Down syndrome can lead to obesity in children.

Obesity - promoting genes and genetics of childhood obesity

Obesity epidemic is regarded as a result of dietary trends which acts on a person's genetic make up to determine body mass and susceptibility to obesity related disease. Childhood obesity have a strong hereditary component. Obesity in general is a disease which is heritable and show strong evidence of a genetic component in its pathogenesis. Every individual's genetic background remains an important determining factor of susceptibility to obesity. Along with genetic component obesity is also influenced by environmental factors. 
The interaction between genetic and environmental factors is of greatest importance as genes exert their influences through behaviours that are directly affected by the social and physical environment. Eating in the absence of hunger is correlated with children's weight status and this behavioural traits seems to be influenced by both genetic and environmental factors. Research has identified genes which plays a significant roles in its etiology. Now it is clear that obesity, in close relatives increases one's risk for obesity, even if the family members do not live together.

With rapid advancement in molecular biology and research work has made us aware of several genetic factors which are considered to be responsible for obesity. Obesity is caused by mutation or chromosomal abnormalities, such as Prader Willi, Bardet-Biedl syndromes and Cohen syndrome.

Normally every individual has one active copy of an imprinted gene. Improper imprinting can result in an individual having two active copies or two inactive copies. This improper imprinting can lead to problems like Prader Willi syndrome which is a complex human genetic disease that arises from lack of expression of paternally inherited imprinted genes on chromosome15q11-q13. Some of the genes in this region are silenced in the egg, and at least one gene is silenced in the sperm. So someone who inherits a defect on chromosome15q11-q13 is missing different active genes, depending on whether the chromosome came from mom or dad. In Prader-Willi syndrome symptoms like learning difficulties, short stratures, and compulsive eating leads to obesity.

In an another research study found that certain parts of the genome were missing in some children with severe obesity and also found that part of chromosome 16 were deleted in some families, and that obesity from a young age was seen in these people. So it was observed that this one particular gene on chromosome16 called SH2B1 plays a key role in regulating weight and also in handling blood sugar levels in people. These people with deletions involving this gene had a strong desire for overeating and gain weight very easily. And this is the first evidence that copy number variants have been linked to a metabolic conditions, such as obesity. This gives a strong undoubtedly evidence that genetic factors play a major role in determining why some people are more likely to gain weight than others.

\section{Metabolic Imprinting and Childhood Obesity Relationship}

Some individual studies have suggested that gestational weight gain also plays significant role in childhood obesities. A large number of studies show that gestational diabetes was estimated to increase chances of youth overweight by $40 \%$.Evidences also suggest that negative events in utero during the prenatal period plays an essential role in determining overweight or obesity later in life. The most common risk factors and conditions that usually affect metabolic programming during the prenatal period are maternal smoking, maternal malnutrition and gestational diabetes. Diabetes in pregnancy is associated with an increased rate of obesity, impaired glucose tolerance, and type 2 diabetes in the offspring childhood. Normally the growth and increase in weight of children's is in proportion to height at an average age of $6 \mathrm{yrs}$. The period of adiposity rebound in age of 13-15 years is said to be crucial period of risk for developing adult obesity and obesity which is seen in childhood is a strong prediction for adult obesity. Many studies also show that raised maternal glycemia during pregnancy is related to increased risk of obesity in childhood.

\section{Maternal smoking during pregnancy and childhood obesity \\ Maternal smoking has been associated with childhood} overweight and obesity, in part because of its association with low birth weight. Research study suggested that maternal smoking during pregnancy might be a risk factor for childhood obesity. A higher skinfold thickness in a $5 \mathrm{yr}$ old children of mothers who smoked during pregnancy has been reported in a cohort study that was done on 530 children. A cross-sectional study performed showed a relationship between maternal smoking during pregnancy and obesity in children.

The occurrence of overweight and obesity in children were calculated by the amount of cigarettes smoked during pregnancy, and the percentages increased with the amount of cigarettes. This studies showed the effect of maternal smoking during pregnancy remained known risk factors for overweight and obesity in children.

During the first year of life, there is rapid catch-up growth regarding weight in children of mothers who smoked during pregnancy. The studies suggest that nicotine inhaled by mother was the cause for childhood obesity and to prove this studies were done on offspring of pregnant rats who were exposed to nicotine and it was seen that they show both appetite learning and attention deficits in them. The alterations of both the cholinergic and catecholaminergic neurotransmitter systems of the brain caused these behavioural effects. It is a known fact that alterations of the cholinergic system have been linked to learning deficits, whereas the catecholaminergic system has been associated with the brain's reward system. It is a known fact that exposure to nicotine in utero due to maternal smoking during pregnancy may affect appetite behaviours of these children where they may be under less control of it than in children of mothers who do not smoke during pregnancy.

\section{Dietary cause of childhood obesity:}

One of the cause for obesity is an imbalance between calories burned. Both these factors, in turn, are influenced by complex gene-environment interactions as children grow and develop in the different sets of circumstances. Significant global shifts in activity levels have also been a key factor too. Excessive watching television, playing video games and using computers is also one of the cause. Children who watch TV for more than 2 hrs per day twice likely to be overweight or obese compared to those who spend one $\mathrm{hr}$ in front of a television screen. Reduced physical education in schools also affects children's activity levels. A very small amount of this food contain high calories and it create limited sensations of fullness, in turn encouraging children to eat more.

Studies has shown that advertising leads children and parents to choose advertised foods. All of these changes worldwide have resulted in many children and families being exposed to "obesogenic environments", where physical activity is discouraged and unhealthy food consumption is encouraged.

\section{Complications and effects of childhood obesity Childhood Obesity May Cause Infertility}

The association between obesity and ovulatory dysfunction 
is well documented. Studies show that childhood obesity disrupts the timing of puberty and may affect fertility in later life. It is seen that obesity can cause early puberty in young girls and this can affect organs like liver, pancreas, endocrine glands which ultimately leads to reproductive system complications.

Childhood obesity affects the neurohormone called kisspeptin that is necessary for reproduction. Normal secretions of this neurohormone get disrupted by endocrine signals from fat that serve to communicate to the brain. The other reason behind early puberty and reproductive abnormalities in obese children is the disruption of circadian clocks which is a natural day and night cycle. This can affect the secretion of hormones-such as cortisol, testosterone and insulin-that cause reproductive abnormalities. Early puberty has a major impact on health of obese girls leading to an increased risk of reproductive cancers, adult -onset diabetes, and metabolic syndrome associated with it.

\section{Childhood obesity causes cardiovascular diseases}

Obesity produces a variety of cardiac structural changes and hemodynamic alterations. Excessive adipose accumulation induces increased blood volume and cardiac output. Obese people who have sleep apnea and obesity related hypoventilation suffers from pulmonary arterial hypertension. In obese people complications like cardiomyopathies is also seen.

\section{Childhood obesity causes hypertension}

Obese persons at any age is prone for hypertension. Childhood obesity is one of the leading cause of paediatric hypertension. Hypertension of obesity is linked to genetic, metabolic, and hormonal factors such as insulin resistance, increased serum aldosterone levels, salt sensitivity and elevated leptin levels.

\section{Childhood obesity can cause asthma and other respiratory problems}

In obese people symptoms of breathlessness and wheezing due to increased work of breathing. Obesity have a direct effect on the mechanical behaviour of the respiratory system by altering compliance or elastic recoil, resulting in reduced effective lung volume, or respiratory muscle strength.

\section{Obesity causes sleep disorders}

It is seen that obese children are 4 -6 times more likely to have obstructive sleep apnea as compared with lean subjects. Obstructive sleep apnea in adults has been related to the development of hypertension and cardiovascular diseases.

\section{Childhood obesity causes orthopedic problems}

Obese children are susceptible to developing bony deformities can lead to other orthopaedic problems in adolescence. Increased weight causes injury to the growth plate and flat kneecap pressure/pain, flat foot, spondylolisthesis (low back pain), scoliosis, and osteoarthritis.

\section{Conclusion}

Childhood obesity is recognised as a major medical and public health problem. The worldwide prevalence of obesity has doubled in the past years and the world is gradually becoming aware of the gravity of the risk that overweight and obesity pose for children's health. The incidence of chronic disease is rapidly increasing in developing countries and a potential threat is emerging incidence of childhood obesity.

Today's youth are living less healthier life and ultimately leading to shorter lives span than their parents and this are the first such instances of reversal in lifespan in modern history. This reversal in the life span is related to increase in obesity in children and has become an issue of utmost public health concern. There has been an alarming and rapid increase in type 2 diabetes mellitus in children, a disease which was previously seen exclusively seen in adults. This type 2 diabetes mellitus is growing worldwide and responsible for upto about one fifth of new diagnoses of diabetes in pubertal children and has become a cause of reversal in life expectancy in modern history.

\section{Homoeopathic management}

1) Calc carb- A big bellied child with emaciated limbs and emaciated limbs and emaciated neck, enlarged glands. They take on flesh and grow flabby. Difficult assimilation.

2) Graphites- Especially adapted to persons inclined to obesity with skin troubles, particularly to females. Solid flesh that belongs to a full blooded, strong individual.

3) Calcostraearum; Constitutionally fat, over- fat or strongly inclined to obesity especially children sluggish or slow, malnutrition. Tendency of obesity in children and young people.

4) Caps: Lack of reaction especially fat people, indolent, weak.

5) Ferrum: Flabby, relaxed and tired children.

Some rubrics found in Kent J.T. repertory are

Section: Generalities

Rubric: obesity

Subrubric: Body fat but legs thin.

Some rubrics found in Murphys repertory are

Section: Generals

Rubric: obesity

Some rubrics found in BTPB are

Section: Sensation

Rubric: Obesity

\section{References}

1. Rudiger von Kries, Andre Micheal Toschkel, Berthold and William Slikker Jr Author Affiliations.

2. Institute of social paediatrics and adolescent medicine, Ludwig Maximilian University of Munich, Munich, Germany.

3. Division of Neurotoxicology, National Center for Toxicological Research, Food and Drug Administration, Jefferson, AR.

4. Indian Pediatrics Jagadesan, et al. Prevalence Of Overweight And Obesity In Chennai. trassition in girls and boys. Reproduction. 2010;140:399.

5. Children's Mental Health Research Quarterly 20 Vol.4,no.1.

6. Mayo Clinic staff. Childhood obesity. Mayoclinic. com. May 4, $2012 \quad$ http://www.mayoclinic. com/health/childhood-obesity/DS00698 
7. World Health Organisation. Obesity: preventing and managing the global epidemic. Report of a WHO consultation, Geneva, 3-5 jun 997. Geneva: WHO; 1998. (WHO/NUT/98.1.)

8. Berenson GS,Srinivasan SR, Wattigney WA, Harsha DW. Obesity and cardiovascular risk in children. Ann NY Acad Sci 1993;699:93-103.

9. PS. Shetty. Nutrition transition in India. Public Health Nutr 2002;5:175-82.

10. BM Popkin. The nutrition transition in low-income countries: An emerging crisis. Nutr Rev 1994;52:28598.

11. Kliegman, Behrman, Jenson, Stanton, Nelson Text Book of Pediatrics. $18^{\text {th }}$ Edition, Published by Elselier India Publications 2008;11:232.

12. Ghai OP, Piyush Gupta VK, Paul Ghai. Essential Pediatrics, Reprint Edition, New Delhi; Published by CBS Publishers and Distributors, 2005, 116. Reddy SR. Effect of homoeopathic medicine Lycopodium clavatum in urinary calculi. International Journal of Applied Research 2017;3(1):790-1.

13. Harrison, Principles of Internal Medicine, International Edition 2001, 479.

14. API Text Book of Medicine, $5^{\text {th }}$ Edition, Mumbai; Published by Association of Physicians of India 1992, 261.

15. Lawrence, Tierney, Jr. Stephen J Mcphee, Current Medical Diagnosis and Treatment. International Edition 2001, 1233.

16. Kent JT. Lectures on Materia Medica. Reprint Edition, New Delhi: B. Jain Publishers Pvt. Ltd 2002, 311-526.

17. Nash EB. Lectures in Homoeopathic Therapeutics. First Edition New Delhi; Published by Indian Books and Periodicals 2006, 73-418.

18. Farrington EA. Clinical Materia Medica. Reprint Edition, New Delhi; Published by Indian Books and Periodicals 2003, 493.

19. Boericke William. Pocket Manual of Homoeopathic MateriaMedica and Repertory, Augmented Edition, New Delhi: B. Jain Publishers Pvt Ltd 2001, 167-361.

20. Murphy Robin ND. Homoeopathic Medical Repertory, Reprint Edition, New Delhi; Indian Books and Periodicals Publishers, 2004, 587pp. Reddy E, Sharma PK, Raj PP. A clinical study on effect of Plantago in gingivitis by assessing bleeding and plaque index.

21. Kent JT. Repertory of Homoeopathic MateriaMedica, $6^{\text {th }}$ Edition, New Delhi; B. Jain Publishers Pvt Ltd 1999, 137.

22. Kliegman Behrman, Jenson Stanton. Nelson Text Book of Pediatrics. $18^{\text {th }}$ Edition, Published by Elselier India Publications 2008;11:232.

23. Ghai OP, Piyush Gupta, Paul VK. Ghai Essential Paediatrics, Reprint Edition, New Delhi; Published by CBS Publishers and Distributors 2005, 116.

24. Allen TF. Boenninghausen Therapeutic Pocket Book, Reprint Edition, New Delhi; B Jain Publishers Pvt Ltd 2006, 169.

25. Barthel. H. Synthetic Repertory. Reprint Edition, New Delhi; Indian Books and Periodicals 2003, 394.

26. Callinan Paul. Family Homoeopathy; New Cannon Conn Keats Publishing Inc 1995.

27. WHO, Preventing and Managing the Global Epidemic, Geneva 1997.

28. National Journal of Homoeopathy, Vol. 6, Mumbai;
Nov-Dec 2004.

29. Homoeopathic Medical Panorama, Journal of Indian Homoeopathic Medical Association, Vol. 13, Kerala, Jan-March 2005.

30. http://en.wikipedia.org/wiki/childhood obesity. 